\title{
Establishing reference values and evaluation of an in-house ferric reducing antioxidant power (FRAP) colorimetric assay in microplates
}

\author{
Yasemin Ustundag ${ }^{1}$, Kagan Huysal ${ }^{1}$, Serdar Kahvecioglu ${ }^{2}$, Hakan Demirci ${ }^{3}$, Senol Yavuz ${ }^{4}$, Murat \\ Sambel $^{5}$, Dursun Unal ${ }^{5}$
}

${ }^{1}$ Department of Clinical Laboratory, Bursa Yuksek Ihtisas Training and Research Hospital, Bursa, Turkey

${ }^{2}$ Department of Nephrology, Bursa Yuksek Ihtisas Training and Research Hospital, Bursa, Turkey

${ }^{3}$ Department of Family Medicine, Bursa Yuksek Ihtisas Training and Research Hospital, Bursa, Turkey

${ }^{4}$ Department of Cardiovascular Surgery, Bursa Yuksek Ihtisas Training and Research Hospital, Bursa, Turkey

${ }^{5}$ Department of Urology, Bursa Yuksek Ihtisas Training and Research Hospital, Bursa, Turkey.

\begin{abstract}
Objectives. The total antioxidant capacity (TAC) of a sample can be measured with a ferric reducing antioxidant power (FRAP) assay. There are commercially available kits for FRAP assays, however they are more expensive than in-house kits. We aimed to evaluate a FRAP direct measurement method under our laboratory conditions using a microplate reader and establish reference values to use in future research projects. Methods. An inhouse microplate adaptation of the FRAP method was evaluated. Reference values of FRAP were established for one hundred and twenty subjects aged between 25-55 years. FRAP levels were estimated in 30 serum samples with high glucose concentration, 44 hyperbiluribinemic neonatals and 16 patients receiving renal replacement therapy (RRT). Results. The mean FRAP level was $890 \pm 235 \mu \mathrm{mol} / \mathrm{L}$. The median TAC level was $904 \mu \mathrm{mol} / \mathrm{L}$. This method was found to be linear up to at least $2000 \mu \mathrm{mol} / \mathrm{L}$. The intra- and inter-assay coefficients of variation were 2.7-6.7\% and 5.3-10.1\%, respectively. The mean FRAP level was lower than normal in diabetes and RRT patients and higher in hyperbiluribinemic neonatals $(687 \pm 209 \mu \mathrm{mol} / \mathrm{L}, 609 \pm 250$ $\mu \mathrm{mol} / \mathrm{L}$ and $945 \pm 187 \mu \mathrm{mol} / \mathrm{L}$, respectively). Conclusions. Our reference values give comparable results with the literature. This method is simple, reliable, and inexpensive. It could be used for studies of oxidative stressrelated diseases.
\end{abstract}

Eur Res $J$ 2016;2(2):126-131

Keywords: Total antioxidant capacity; ferric reducing antioxidant power; evaluation; reference range; microplate 


\section{Introduction}

Reactive oxygen species (ROS) are produced in the human body as a consequence of normal aerobic metabolism and a balance between production and inactivation is required. Excess production of ROS can lead to a situation of oxidative stress, which is responsible for many pathological processes and has an impact on the body's aging process. Oxidative damage has been implicated in the cause of many diseases, including cardiovascular disease, diabetes, neuronal degeneration, depression, cancer and probably aging [1-3].

To protect cells against oxidative stress, certain low molecular weight antioxidant molecules, either water-soluble (e.g., ascorbic acid) or lipid-soluble (e.g., vitamin E), are present in extracellular fluids [2, 3]. The concentrations of antioxidants can be measured separately but this is not practical since their antioxidant effects are additive. The sum of endogenous and food-derived antioxidants represents the total antioxidant capacity of the extracellular fluid. The total antioxidant capacity of a sample can be measured, termed the total antioxidant capacity (TAC), which is the sum of endogenous and foodderived antioxidants [4].

Several methods have been developed to measure TAC, and the most common of these methods are the oxygen radical absorbance capacity (ORAC), ferric reducing antioxidant power (FRAP) and the total radical trapping antioxidant potential (TRAP) [5-7]. A FRAP spectrophotometric assay can be performed using the method developed by Benzie and Strain [8]. FRAP is a simple and relatively inexpensive test that measures the ability of antioxidants to reduce ferric iron. At low $\mathrm{pH}$, excess FeIII in the reaction mixture is reduced to the ferrous form and color formation is directly related to the reducing ability of the sample. The results are highly reproducible over a wide concentration range [8].

A microplate adaptation of the FRAP method has been described previously [9]. There are commercially available kits for the FRAP assay, however they are more expensive than in-house kits $[10,11]$. We aimed to evaluate a FRAP direct measurement method under our laboratory conditions using a microplate reader and establish reference values to use in future research projects $[10,11]$.

\section{Methods}

All measurements were carried out according to the tenets of the Declaration of Helsinki (2013 Brazil version) of the World Medical Association. This study was approved by the Bursa Yuksek Ihtisas Training and Research Hospital ethics committee, and all participants signed written informed consent forms before the study began.

Microplate Analysis Using Ferric Tripyridyl Triazine

The FRAP assay of Benzie and Strain is based on the principle that at low $\mathrm{pH}$, the ferric tripyridyl triazine (FeIII TPTZ) complex gets reduced to the ferrous form, developing an intense blue color with a maximum absorption at $593 \mathrm{~nm}$.

The FRAP reagent was prepared by mixing 300 $\mathrm{mmol} / \mathrm{L}$ acetate buffer ( $\mathrm{pH}-3.6), 10 \mathrm{mmol} / \mathrm{L}$ TPTZ [2,4,6-tri(2-pyridyl)-s-triazine] solution, and 20 $\mathrm{mmol} / \mathrm{L} \mathrm{FeCl}_{3}$ solution in a 10:1:1 ratio. All chemicals were purchased from Sigma-Aldrich Ltd. (St Louis, MO). $20 \mu \mathrm{L}$ of sample (serum or plasma) was mixed with $300 \mu \mathrm{L}$ of FRAP reagent; after 10 minutes of incubation at $37 \mathrm{o} \mathrm{C}$, the ferric tripyridyl triazine (FeIII -TPTZ) complex is reduced to the ferrous tripyridyl triazine (FeII-TPTZ) form in the presence of antioxidants. Absorbance was measured with a Readwell Touch Elisa plate analyzer (Robonik PVT Ltd. Mumbai, India). Known solutions of FeII (FeSO4X7H2O) in the range of 250-2000 $\mu \mathrm{mol} / \mathrm{L}$ were used for calibration.

\section{Method Verification Studies}

Method verification studies were performed to determine if the assay fulfilled the specified requirements [12].

\section{a) Limit of Detection}

The detection limit of the method was determined by evaluating the zero calibrators 20 times. The detection limit was defined as the mean value of the zero calibrators $+3 \mathrm{SD}$.

\section{$\mathrm{LOD}=$ Xblank +3 (SD blank) $[12,13]$}

\section{b) Limit of Blank}

Limit of Blank (LoB) was the highest apparent analyte concentration expected to be found when 


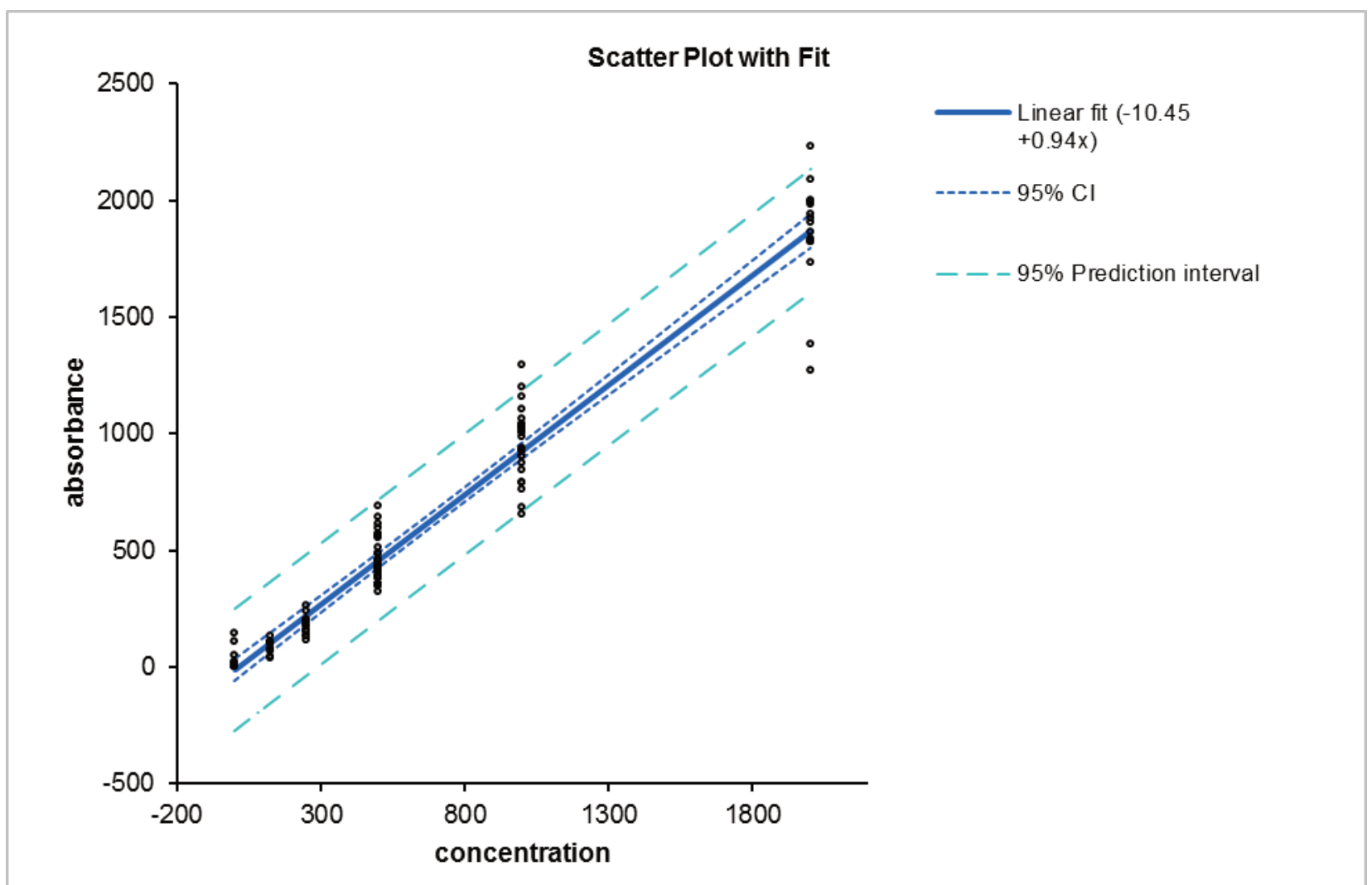

Figure 1. Linear plot of serial dilutions of ferric sulphate solution.

replicates of a sample containing no analyte were tested. LoB was estimated by measuring replicates of a blank sample and calculating the mean result and the standard deviation (SD). $\mathrm{LoB}=$ mean blank +1.645 (SD blank) $[12,13]$.

\section{c) Linearity}

Serial dilutions of the $250-2000 \mu \mathrm{mol} / \mathrm{L}$ ferric sulphate solutions were used for linearity analysis (Figure 1).

\section{d) Precision}

To evaluate the precision of the study, reproducibility was tested for both samples and standards. All four standards were run in 4 replicates for 20 days to determine the total coefficient of variation (between run) (Table 1). Also, four randomly chosen samples over three days were run in duplicate (Table 2).

\section{e) Recovery of Serum Samples}

Recovery was determined with a diluted serum sample having a known high FRAP activity and another with a lower FRAP activity and mixing them in the ratios given in Table 3. Mean recovery was determined in percent $(\%)$.

\section{f) Reference Interval}

To determine the reference interval for serum TAC, serum specimens from 120 healthy individuals (41 women, 79 men, 25-55 years old) were assayed [14]. They were on an average diet and were nonsmokers, but we have no information on their nutritional habits. Kolmogorov-Smirnov test was used

Table 1. Precision values for the FRAP assay. Sample; standard mean of 20 days 4 times a day

\begin{tabular}{llll}
\hline Standard value & Mean $(\boldsymbol{\mu m o l} / \mathbf{L})$ & SD & CV (\%) \\
\hline $2000 \mu \mathrm{mol} / \mathrm{L}$ & 1923 & 148 & 7.6 \\
$1000 \mu \mathrm{mol} / \mathrm{L}$ & 987 & 91 & 9.2 \\
$500 \mu \mathrm{mol} / \mathrm{L}$ & 489 & 59 & 12.0 \\
$250 \mu \mathrm{mol} / \mathrm{L}$ & 205 & 38 & 18.5 \\
\hline
\end{tabular}

$\mathrm{CV}=$ coefficient of variation, $\mathrm{FRAP}=$ ferric reducing antioxidant power, $\mathrm{SD}=$ deviation of standard 
Table 2. Intra-day and inter-day precision values for the FRAP assay using patient sample. Sample; human serum mean of 3 assays

\begin{tabular}{ccccccc}
\hline TAC & \multicolumn{3}{c}{ Within-day } & \multicolumn{3}{c}{ Between-day } \\
\hline & Mean $(\mu \mathrm{mol} / \mathrm{L})$ & SD & CV $(\%)$ & Mean $(\mu \mathrm{mol} / \mathrm{L})$ & SD & CV $(\%)$ \\
\hline Sample 1 & 665 & 18 & 2.7 & 648 & 44 & 6.7 \\
Sample 2 & 1081 & 41 & 3.7 & 1088 & 86 & 7.9 \\
Sample 3 & 473 & 32 & 6,7 & 495 & 50 & 10.1 \\
Sample 4 & 642 & 23 & 3.5 & 615 & 33 & 5.3 \\
\hline
\end{tabular}

$\mathrm{CV}=$ coefficient of variation, $\mathrm{FRAP}=$ ferric reducing antioxidant power, $\mathrm{SD}=$ deviation of standard, $\mathrm{TAC}=$ total antioxidant capacity

Table 3. Recovery was determined by a diluted serum sample with a known high FRAP activity and another with a lower FRAP activity

\begin{tabular}{lllll}
\hline $\begin{array}{l}\text { Low } \\
\text { Sample }\end{array}$ & $\begin{array}{l}\text { High } \\
\text { Sample }\end{array}$ & $\begin{array}{l}\text { Observed } \\
\text { Concentration }\end{array}$ & $\begin{array}{l}\text { Expected } \\
\text { Concentration }\end{array}$ & $\begin{array}{l}\text { Recovery } \\
(\%)\end{array}$ \\
\hline $80 \%$ & $20 \%$ & $431 \mu \mathrm{mol} / \mathrm{L}$ & $439 \mu \mathrm{mol} / \mathrm{L}$ & 99.0 \\
$60 \%$ & $40 \%$ & $522 \mu \mathrm{mol} / \mathrm{L}$ & $562 \mu \mathrm{mol} / \mathrm{L}$ & 92.8 \\
$40 \%$ & $60 \%$ & $646 \mu \mathrm{mol} / \mathrm{L}$ & $688 \mu \mathrm{mol} / \mathrm{L}$ & 94.1 \\
$20 \%$ & $80 \%$ & $806 \mu \mathrm{mol} / \mathrm{L}$ & $816 \mu \mathrm{mol} / \mathrm{L}$ & 98.7 \\
\cline { 3 - 5 } & & & Mean recovery & 96.3 \\
\hline
\end{tabular}

FRAP $=$ ferric reducing antioxidant power

to evaluate variance and normality of the data.

\section{Patients}

A total of 30 plasma samples were collected from the patients where blood glucose levels were found to be high. Diabetic patients are well known to have decreased TAC levels [15]. The level of TAC was estimated in all these 30 samples. Low TAC was also provided from chronic kidney failure patients after a renal replacement treatment session [16].

Samples of infants with neonatal icterus were selected as an indicator of high TAC levels [8]. Because it is hard to obtain neonatal serum, leftover serum samples were used for this group [17]. We did not obtain permission from the parents of neonatal patients. Because we do not have access to patients' private information, this research, by definition, would not be human subject research and would not require informed consent from neonates or parents [18].

\section{Results}

In the regression analyses with ferric sulphate solutions, the $\mathrm{r}^{2}$ value was 0.95 , the slope was 0.94 ( $p<$ 0.001 ), and the intercept was -10.45. Analytical sensitivity, which is the slope of the calibration line, was 0.94 (Figure 1).

The FRAP assay had a limit of detection of 26.1 $\mu \mathrm{mol} / \mathrm{L}$ of antioxidant power and the limit of the blank was $17.2 \mu \mathrm{mol} / \mathrm{L}$.

The intra-day assay coefficient of variation was $6.7-2.7 \%$ and the inter-day reproducibility was between $5.3-10.1 \%$ for the samples (Table 2). The intra-day assay coefficient of variation for standards was $7.6-18.5 \%$. Recovery is given as $96.3 \%$ (see Table $3)$.

Human serum samples had FRAP concentrations that ranged from 419 to $1392 \mu \mathrm{mol} / \mathrm{L}$, with a mean level of $890 \mu \mathrm{mol} / \mathrm{L}$, a median of $904 \mu \mathrm{mol} / \mathrm{L}$ and showed a normal distribution (Kolmogorov-Smirnov test result, $p=0.085$ ) in healthy subjects.

Patient with diabetes (fasting value more than 120 $\mathrm{mg} / \mathrm{dL}$, median 167 (inter quartile range: 200) mg/dL) and chronic kidney failure patients after a renal replacement treatment session had FRAP values of $687 \pm 193$ and $609 \pm 250 \mu \mathrm{mol} / \mathrm{L}$, respectively. In neonatal hyperbilirubinemic patients FRAP values were high; $945 \pm 187 \mu \mathrm{mol} / \mathrm{L}$.

\section{Discussion}

In this study, TAC levels in serum were between 
419 and $1392 \mu \mathrm{mol} / \mathrm{L}$ using the FRAP method in healthy subjects 25 to 55 years old. Whether FRAP levels varies with gender and with increase in age was not evaluated in this study. Our result is similar to the findings of Karajibani et al. [19], who reported a mean value of $789 \mu \mathrm{mol} / \mathrm{L}$ with a SD of $158.5 \mu \mathrm{mol} / \mathrm{L}$, and Mistry et al. [10] who found a median of $741.2 \mu \mathrm{mol} / \mathrm{L}$ (range: 651.6-848.1) with a commercial kit (DetectX FRAP colorimetric detection assay K043-H1, Arbor Assays) in 472 healthy adult women. Benzie and Strain [8] found a plasma FRAP value of $1000 \pm 206$ $\mu \mathrm{mol} / \mathrm{L}$ in 141 apparently healthy Chinese adults and Kumar et al. [20] reported a value of $1005 \pm 203.23$ $\mu \mathrm{mol} / \mathrm{L}[20]$.

The level of oxidative indices may differ depending on the ethnicity, as observed in previous investigations [21]. The difference between studies might be associated with different diets. It is known that Mediterranean diet intervention increases plasma the total antioxidant capacity level in subjects $[22,23]$. However, we did not question our study population about their eating habits.

In this study, absorbance was measured in an Elisa plate analyzer at $560 \mathrm{~nm}$ whereas Benzie and Strain [8] measured the absorbance at $593 \mathrm{~nm}$ in a spectrophotometer. As most of the Elisa plate analyzers do not have filters to measure the absorbance at $593 \mathrm{~nm}$, the nearest wavelength of 560 nm was chosen in this study. Thus, the method became applicable and for the commercial Elisa kits $560 \mathrm{~nm}$ absorbance was determined as well $[10,11]$.

The linearity beyond $2000 \mu \mathrm{mol} / \mathrm{L}$ was not determined since none of the data from the healthy volunteers and patients was above $2000 \mu \mathrm{mol} / \mathrm{L}$, and none of the results were below $288 \mu \mathrm{mol} / \mathrm{L}$.

Mistry et al. [10] reported that with a commercial kit, the workable assay range was 31.25-1000 $\mu \mathrm{mol} / \mathrm{L}$ and the inter- and intra-assay coefficients of variation were 9.3 and $4.3 \%$, respectively. Our inter- and intraassay coefficients of variation were higher [10].

In our study, serum FRAP values were found to be low in patients with diabetes and chronic kidney disease patients after renal replacement therapy with hemodialysis. Previous studies have revealed a significant imbalance of pro-oxidants and antioxidants in patients with CKD and diabetes [15, 16, 19, 24, 25]. It is also well known that bilirubin shows an antioxidant capacity, as in neonatal patients with increased bilirubin levels [26-28].

\section{Conclusions}

Our reference values gave results comparable to the literature. This method is simple, reliable, and inexpensive. It could be used for studies of oxidative stress-related diseases.

\section{Conflict of interest}

The authors disclosed no conflict of interest during the preparation or publication of this manuscript.

\section{Financing}

The authors disclosed that they did not receive any grant during conduction or writing of this study.

\section{References}

[1] Rahal A, Kumar A, Singh V, Yadav B, Tiwari R, Chakraborty S, et al. Oxidative stress, prooxidants, and antioxidants: the interplay. Biomed Res Int 2014;2014:761264.

[2] Lubrano V, Balzan S. Enzymatic antioxidant system in vascular inflammation and coronary artery disease. World J Exp Med 2015;5:218-24.

[3] Liu T, Zhong S, Liao X, Chen J, He T, Lai S, et al. A Metaanalysis of oxidative stress markers in depression. PLoS One 2015; 10:e0138904.

[4] Rysz J, Stolarek RA, Pedzik A, Nowicki M, Nowak D. Serum antioxidant capacity is preserved in peritoneal dialysis contrary to its robust depletion after hemodialysis and hemodiafiltration sessions. Ther Apher Dial 2010;14:209-17.

[5] Jansen EH, Ruskovska T. Comparative analysis of serum (anti)oxidative status parameters in healthy persons. Int $\mathrm{J}$ Mol Sci 2013;14:6106-15.

[6] Woudberg NJ, Goedecke JH, Blackhurst D, Frias M, James $\mathrm{R}$, Opie LH, et al. Association between ethnicity and obesity with high-density lipoprotein (HDL) function and subclass distribution. Lipids Health Dis 2016;15:92.

[7] Bortolasci CC, Maes M, Vargas HO, Souza-Nogueira A, Moreira EG, Nunes SO, et al. Paraoxonase 1 status and interactions between Q192R functional genotypes by smoking contribute significantly to total plasma radical trapping antioxidant potential. Neurosci Lett 2014;581:46-51.

[8] Benzie IF, Strain JJ. The ferric reducing ability of plasma (FRAP) as a measure of "antioxidant power": the FRAP assay. Anal Biochem 1996;239:70-6.

[9] Lim CSH, Lim SL. Ferric reducing capacity versus ferric reducing antioxidant power for measuring total antioxidant capacity. Lab Med 2013;44:51-5.

[10] Mistry HD, Gill CA, Kurlak LO, Seed PT, Hesketh JE, Meplan C, et al. Association between maternal micronutrient status, oxidative stress, and common genetic variants in antioxidant enzymes at 15 weeks' gestation in nulliparous women who subsequently develop preeclampsia. Free Radic Biol Med 2015;78:147-55.

[11] Adjei-Fremah S, Jackai LEN, Worku M. Analysis of phenolic content and antioxidant properties of selected cowpea 
varieties tested in bovine peripheral blood. Am J Animal Vet Sci 2015;10:235-45.

[12] Topic E, Nikolac N, Panteghini M, Theodorsson E, Salvagno GL, Miler M, et al. How to assess the quality of your analytical method? Clin Chem Lab Med 2015;53:1707-18.

[13] Shrivastava A, Gupta VB. Methods for the determination of limit of detection and limit of quantitation of the analytical methods. Chron Young Sci 2011;2:21-5.

[14] Guidi GC, Salvagno GL. Reference intervals as a tool for total quality management. Biochem Med 2010;20:165-72.

[15] Korkmaz GG, Konukoglu D, Kurtulus EM, Irmak H, Bolayirli M, Uzun H. Total antioxidant status and markers of oxidative stress in subjects with normal or impaired glucose regulation (IFG, IGT) in diabetic patients. Scand J Clin Lab Invest 2013;73:641-9.

[16] Zargari M, Sedighi O. Influence of hemodialysis on lipid peroxidation, enzymatic and non-enzymatic antioxidant capacity in chronic renal failure patients. Nephrourol Mon 2015;7:e28526.

[17] Ridefelt P, Hellberg D, Aldrimer M, Gustafsson J. Estimating reliable paediatric reference intervals in clinical chemistry and haematology. Acta Paediatr 2014;103:10-5.

[18] Allen MJ, Powers ML, Gronowski KS, Gronowski AM. Human tissue ownership and use in research: what laboratorians and researchers should know. Clin Chem 2010;56:1675-82.

[19] Karajibani M, Hashemi M, Montazerifar F, Bolouri A, Dikshit M. The status of glutathione peroxidase, superoxide dismutase, vitamins A, C, E and malondialdehyde in patients with cardiovascular disease in Zahedan, Southeast Iran. J Nutr Sci Vitaminol (Tokyo) 2009;55:309-16.

[20] Kumar A, Mishra AK, Rana A, Yadav P. Correlation between oxidative stress and serum iron level in pregnant anemic women in north Indian population. GJRA 2015;4:325-27.
[21] Fisher G, Alvarez JA, Ellis AC, Granger WM, Ovalle F, Man $\mathrm{CD}$, et al. Race differences in the association of oxidative stress with insulin in African- and European-American women. Obesity (Silver Spring) 2012;20:972-7.

[22] Carrion-Garcia CJ, Guerra-Hernandez EJ, Garcia-Villanova B, Molina-Montes E. Non-enzymatic antioxidant capacity (NEAC) estimated by two different dietary assessment methods and its relationship with NEAC plasma levels. Eur J Nutr 2016.

[23] Zamora-Ros R, Serafini M, Estruch R, Lamuela-Raventos RM, Martínez-Gonzalez MA, Salas-Salvado J, et al; PREDIMED Study Investigators. Mediterranean diet and non enzymatic antioxidant capacity in the PREDIMED study: evidence for a mechanism of antioxidant tuning. Nutr Metab Cardiovasc Dis 2013;23:1167-74.

[24] Gupta S, Gambhir JK, Kalra O, Gautam A, Shukla K, Mehndiratta M, et al. Association of biomarkers of inflammation and oxidative stress with the risk of chronic kidney disease in type 2 diabetes mellitus in North Indian population. J Diabetes Complications 2013;27:548-52.

[25] Patel V, Kanani D, Chauhan K, Haridas N, Makadia M, Patel V. Assessment of oxidative stres in type 2 diabetes mellitus by measurement of plasma lipid hydroperoxides and total antioxidant capacity. Int J Adv Res 2015;3:1078-84.

[26] Gopinathan V, Miller NJ, Milner AD, Rice-Evans CA. Bilirubin and ascorbate antioxidant activity in neonatal plasma. FEBS Lett 1994; 1;349:197-200.

[27] Dogan M, Peker E, Kirimi E, Sal E, Akbayram S, Erel O, et al. Evaluation of oxidant and antioxidant status in infants with hyperbilirubinemia and kernicterus. Hum Exp Toxicol 2011;30:1751-60.

[28] Liao SL. The role of bilirubin and phototherapy in the oxidative/antioxidant balance. Pediatr Neonatol 2015;56:77-8. 